\title{
Actinomycosis of the orbit
}

\author{
Timothy J Sullivan, G W Aylward, J E Wright
}

\begin{abstract}
Actinomycosis is a very rare cause of orbital abscess usually attributable to direct spread from adjacent structures. A case of actinomycosis of the orbit is presented, which was treated as orbital pseudotumour for 3 months before progression of signs and symptoms, despite high dose steroids, led to the diagnosis being reconsidered.
\end{abstract}

(Brf Ophthalmol 1992; 76: 505-506)

\section{Case report}

A 42-year-old Caucasoid woman was referred to a neurologist with a 3 week history of a right temporal headache, radiating around her right eye. For the past 5 years the vision in the right. eye had been counting fingers, because of a macular scar of unknown aetiology.

Computed tomography (CT) of the head failed to show any abnormality. She was placed on oral dexamethasone to relieve the pain and made a dramatic symptomatic response. As the steroid dosage was reduced she developed right periocular tenderness, proptosis, and eyelid swelling.

She was admitted for further investigation. The erythrocyte sedimentation rate (ESR) was $70 \mathrm{~mm} / \mathrm{h}$, there was a mild leucocytosis, and lumbar puncture was normal. While she was an inpatient her right second upper molar tooth fractured spontaneously; infection of the affected tooth was not evident on dental examination or $x$ ray. Orbital CT showed a small ill-defined mass, isodense with brain, in the posterolateral part of the right orbit (Fig 1). She was seen by an ophthalmologist, who commenced antibiotics in view of the elevated ESR and leucocytosis. Another ophthalmologist believed she had orbital pseudotumour and recommenced her on high dose steroids, with another dramatic improvement. The proptosis progressed and the

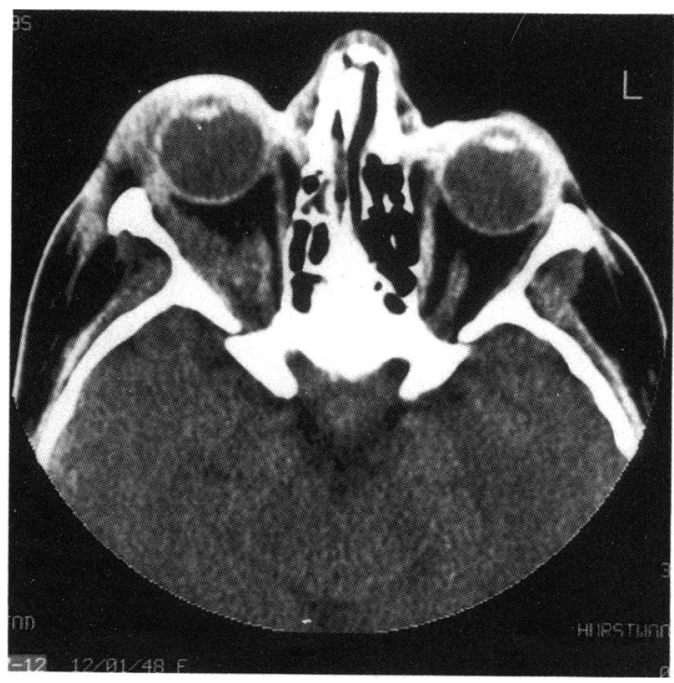

headache and pain returned, however, when the steroid dosage was reduced.

At the time of referral to the orbital clinic (Fig 2) the right visual acuity was reduced to counting fingers and the left eye was normal, with a visual acuity of Snellen 6/9. There was a right afferent pupillary defect and a right central scotoma.

There were $5 \mathrm{~mm}$ of right relative proptosis, decreased right corneal sensation, and complete loss of right ocular ductions. A small scar was present at the right macular but the optic disc and retinal vessels were normal.

At the time of orbital exploration, through a lateral canthotomy approach, an abscess (containing green pus) was encountered within the inner surgical space. The abscess was drained and the patient was given metronidazole and high dose intramuscular penicillin $\mathrm{V}$ with probenecid. Gram stain revealed actinomycosis and culture grew a pure heavy growth of Actinomyces israelii.

Three months postoperatively the patient was well with no proptosis, a moderate right ptosis, and a mild right abduction weakness.

\section{Discussion}

This rare case of orbital actinomycosis was presumed to result from direct extension of an endogenous infection of the oral cavity, probably related to the carious tooth that later fractured. Several reports of orbital actinomycosis in the older literature exist ${ }^{1-6}$; however we were unable to trace any recent reports of orbital actinomycosis, although one case of Tolosa-Hunt syndrome reported in 1979 was attributed to

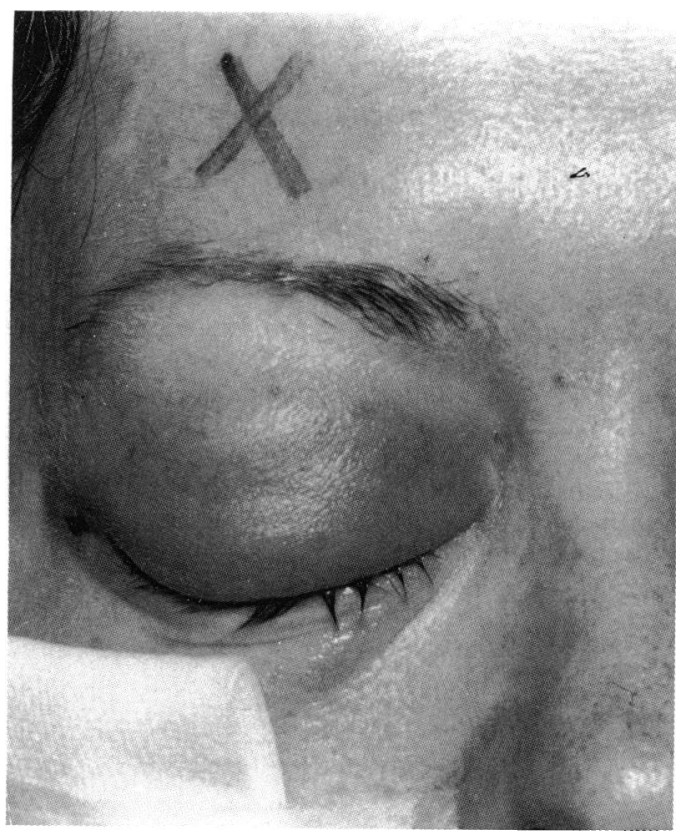

Figure 2 Prior to orbital exploration there was right proptosis and soft tissue swelling closing the right eye.
Figure 1 Orbital CT showed a small ill-defined mass, isodense with brain, in right orbit.
Orbital Clinic,

T J Sullivan

JE Wright

Mr J E Wright, Moorfields Eye ECIV 2PD.

Accepted for publication

3 February 1992 
Actinomyces israelii. ${ }^{7}$ This decrease in incidence has been attributed to better oral hygiene and the widespread use of broad-spectrum antibiotics. Actinomyces israelii, a higher bacteria with some fungal characteristics, forms part of the normal flora of the oral cavity. ${ }^{8}$ Rarely the orbit may become involved secondarily from infections of the infratemporal fossa, the paranasal sinuses, or ocular adnexal structures. ${ }^{9}$ In contrast to this case, orbital actinomycosis usually presents with painless proptosis and restricted extraocular movements. Fistulas and sinus formation may follow.' Treatment of actinomycosis usually consists of high dose penicillin, or clindamycin or chloramphenicol in patients with an allergy to penicillin.

This case illustrates the danger of treating patients with a presumed diagnosis of pseudotumour with a trial of steroids without prior surgical exploration and biopsy. ${ }^{10-12}$ Such an approach often masks the true nature of the orbital lesion and delays correct therapy. ${ }^{13} 14$

$\mathrm{Mr}$ Sullivan is supported in part by the RACO/OPSM fellowship. The authors thank Mr G E Rose for reviewing the manuscript.
1 Ransom WB. A case of actinomycosis of the orbit, with a summary of seven other cases of actinomycosis. Br Med $\mathcal{F}$ $1896 ; 1: 1553-5$

2 Cavara V. Le micosi ocular. Siena: Tip S Bernadino, 1928.

2 Cavara V. Le micosi ocular. Siena: Tip S Bernadino, 1928. 1933; 10: 664-73.

4 Cope Z. Actinomycosis. London: Oxford University Press, 1938: 71-7.

5 Veirs ER, Davis CT. Fungus infections of the eye and orbit. Arch Ophthalmol 1958; 59: 172-6.

6 Francois J, Elewaut-Rysselaere M. Infections actinomycetiques. Bull Soc Belge Ophtal 1968; 148: 117-44.

7 Dorman TL, Espir MLE, Gale EAM, Tattersall RB Worthington BS. Remittent painful ophthalmoplegia: the Tolosa-Hunt syndrome? A report of seven cases and review of the literature. $\mathcal{F}$ Neurol Neurosurg Psychiat 1979; 42: $270-5$.

8 Emmons CW, Binford CH, Utz JP, Kwon-Chung KJ. Medical mycology, 3rd ed. Philadelphia: Lea and Febiger, 1977: 7693.

9 Duke-Elder S, MacFaul PA. Actinomycosis. In: Duke-Elde S, ed. System of Ophthalmology, Vol XIII, part II, Lacrimal,
orbital and para-orbital diseases. London: Kimpton, 1974; 910-3.

10 Hearsink B, Rodrigues MR, Flanagan JC. Inflammatory pseudotumor of the orbit. Ann Ophthalmol 1977; 9: 17-29.

11 Jakobiec FA, Jones IS. Orbital inflammations. In: Duane TD Jaeger EA, eds. Clinical ophthalmology. Philadelphia: Lippincott, 1988: Vol 2, Chapter 35.

12 Leone CR Jr, Lloyd WC III. Treatment protocol for orbital inflammatory disease. Ophthalmology 1985; 92: 1325-31.

13 Spoor TC, Hartel WC, Harding S, Kocher G. Aspergillosis presenting as a corticosteroid responsive optic neuropathy. presenting as a corticosteroid responsive

14 Slavin ML. Primary aspergillosis of the orbital apex. Arch Ophthalmol 1991; 109: 1502-3. 